\title{
BMJ Open Youth tobacco access: trends and policy implications
}

\author{
Philip Gendall, ${ }^{1}$ Janet Hoek, ${ }^{1}$ Louise Marsh, ${ }^{2}$ Richard Edwards, ${ }^{3}$ Benjamin Healey ${ }^{4}$
}

To cite: Gendall P, Hoek J, Marsh L, et al. Youth tobacco access: trends and policy implications. BMJ Open 2014;4:e004631. doi:10.1136/bmjopen-2013004631

- Prepublication history for this paper is available online. To view these files please visit the journal online (http://dx.doi.org/10.1136/ bmjopen-2013-004631).

All authors are members of the ASPIRE2025

collaboration (http://www. aspire2025.co.nz).

Received 6 December 2013 Revised 26 March 2014 Accepted 27 March 2014

CrossMark

\footnotetext{
${ }^{1}$ Department of Marketing, University of Otago, Dunedin, Otago, New Zealand

${ }^{2}$ Cancer Society Social and Behavioural Research Unit, Department of Preventive and Social Medicine, University of Otago, Dunedin, Otago,

New Zealand

${ }^{3}$ Department of Public Health, University of Otago, Wellington, New Zealand ${ }^{4}$ Department of Marketing, University of Otago, Wellington New Zealand
}

Correspondence to Professor Janet Hoek; janet.hoek@otago.ac.nz

\section{ABSTRACT}

Objective: We examined whether the supply routes via which New Zealand adolescents aged 14-15 years accessed tobacco had changed during a period of dynamic policy activity.

Setting: We analysed data from seven consecutive years (2006-2012) of the New Zealand Action on Smoking and Health (ASH) Year 10 survey, a nationwide cross-sectional annual survey.

Participants: All New Zealand schools teaching Year 10 students are invited to participate in the survey; school-level participation rates have ranged between $44 \%$ and $58 \%$ and more than 25000 students have responded to the survey in each year. The results presented draw on the subsample who reported smoking when surveyed ( $N \sim 9200)$. The data were weighted by age, ethnicity and school socioeconomic status (SES) to remove effects of systematic overresponse by New Zealand Europeans and underresponse by those in lower SES groups from trend analyses.

\section{Primary and secondary outcome measures:}

The survey measured adolescents' main reported tobacco supply source.

Results: Smoking prevalence declined significantly $(8.1 \%)$ over the period examined (linear tend coefficient: $-0.74 ; 95 \% \mathrm{Cl}-1.03$ to -0.45 , significant $\mathrm{p}<0.01)$. Friends showed a significant decline in relative importance as a supply source while caregivers and other sources showed a significant increase over the period examined.

Conclusions: The findings show that social supply, particularly via friends, caregivers and others, such as older siblings, is a key tobacco source for adolescents; commercial supply is much less important. The findings raise questions about the additional measures needed to reduce smoking among youth. Endgame policies that make tobacco more difficult to obtain and less appealing and convenient to gift merit further investigation.

\section{INTRODUCTION}

Despite their avowals to the contrary, tobacco companies have always had a strong interest in youth smoking for the simple reason that, over the long term, young people offer them the greatest potential profit. ${ }^{12}$ The age at which adolescents begin smoking influences their

\section{Strengths and limitations of this study}

- Our access to seven consecutive years of crosssectional data obtained during a period of considerable policy activity allowed examination of how adolescents' tobacco sources changed in response to policy interventions.

- The data illustrate how tobacco supply sources vary by socioeconomic status and ethnicity and suggest continued excise tax increases may play an important role in reducing supply from parents, caregivers and older siblings.

- The small proportion of adolescents that reported accessing tobacco from commercial sources highlights the potential stronger denormalisation measures could have for deterring the social supply of tobacco.

- Changes in the question response categories may have altered the response distributions in 2011 and 2012, but this seems unlikely to explain the significant changes in the patterns of source of supply.

- The questionnaire did not ask respondents about all the sources they used to access tobacco but instead examined their main source only. However, given the importance of friends as a supply source, it seems unlikely the overall patterns would change greatly had a multiple response question been used.

progress to nicotine dependence and the number of years they will smoke, ${ }^{3}$ the number of cigarettes they will smoke each day as adults, ${ }^{4}$ their likelihood of quitting ${ }^{5}$ and the chances they will die prematurely from a smoking-related illness. ${ }^{6}$ As preventing smoking initiation among youth eliminates the myriad health risks they would face as adult smokers, many countries have implemented policies to deter youth smoking initiation.

Findings that youth have historically found it easy to purchase tobacco products has prompted policymakers to restrict access to retail tobacco sources by prohibiting sales to minors. ${ }^{78}$ Reported purchasing from commercial sources has declined following the introduction of these restrictions, ${ }^{9} 10$ although widespread reductions in youth smoking prevalence have not always resulted. ${ }^{11-13}$ 
Some researchers maintain that comprehensive youth access restrictions have directly reduced smoking prevalence and recommend more rigorous compliance checks and stricter penalties for transgressors to reduce smoking initiation further. ${ }^{14}{ }^{15}$ However, others demur and offer alternative views. Among the latter, one school suggests access restrictions create and reinforce perceptions that tobacco is difficult to obtain; these, in turn, denormalise smoking by reducing its perceived acceptability and prevalence. ${ }^{16}$ As commercial access to tobacco is a strong predictor of whether a young person would supply tobacco to others, ${ }^{17} 18$ youth access restrictions appear likely to reduce young people's ability to supply others.

Yet others argue that retail access restrictions are insufficiently comprehensive to have had a sustained or marked effect on behaviour, and claim investment in other tobacco control measures would provide better returns. ${ }^{13}$ 19-21 As enforcement must reach a high threshold before it is effective, ${ }^{120}$ this school of thought recommends interventions that target the entire population. ${ }^{11}$

Debate over youth access restrictions is also complicated by the evaluation measures used to assess retailer compliance, which often do not replicate the strategies young people employ to obtain tobacco from commercial sources. ${ }^{11} 2223$ Further, the tobacco industry's support for youth access restrictions suggests these measures may have little effect on smoking prevalence ${ }^{13} 20$ and, ironically, may deflect attention from the industry's deceptive behaviours. ${ }^{12}$

Overall, youth access restrictions appear to reduce prevalence directly only when very high levels of compliance are achieved, ${ }^{21}$ and continued focus on this measure may overlook the role social sources play in maintaining tobacco supply to young people. ${ }^{7}{ }^{12} 24-26$ Peers, family and even strangers are important sources of tobacco for young experimental smokers. ${ }^{23} 2728$ Commercial supply does become more important as nicotine addiction develops and smoking frequency increases, ${ }^{23} 2930$ but friends and peers remain the key supply routes adolescents use to procure tobacco, ${ }^{10} 31$ even as their smoking frequency increases and they require more diverse sources to satisfy their growing addiction. ${ }^{172329} 32$

Social supply not only influences smoking initiation, experimentation and progression to regular smoking, but may also be the main source of tobacco among early adolescent smokers. ${ }^{25} 2632$ This evidence has stimulated interest in how social supply functions, which sources are most important and whether source importance varies as other elements of the policy environment change. ${ }^{32}$ For example, we currently know little about whether or how supply routes vary following excise tax increases, which may raise commercial supply barriers (particularly for young smokers with limited income) and promote more diverse tobacco access strategies.
New Zealand's innovative tobacco policy environment makes it a salient setting to investigate how youth source tobacco and whether access strategies have changed over time. Youth smoking prevalence in New Zealand has fallen consistently in recent years; in 2006, $14.2 \%$ of 14 and 15-year-olds smoked regularly while only $7.7 \%$ reported doing so in 2012; and daily smoking halved from $8.2 \%$ in 2006 to $4.1 \%$ in 2012 . Nevertheless, even in $2012,17.3 \%$ of 14 and 15-year-olds reported experimenting with tobacco. ${ }^{33}$

Our analysis examines trends in tobacco supply sources in New Zealand from 2006 to 2012, a period of considerable policy activity. Developments included the introduction of pictorial warning labels in 2008, a tax increase of $10 \%$ on factory made cigarettes and $24 \%$ on loose leaf tobacco in April 2010, followed by further increases of $10 \%$ on 1 January 2011 and then again on 1 January 2012. In addition, in March 2011 the government announced a goal that New Zealand would become a smoke-free nation by 2025 (where smoking prevalence falls below 5\%). ${ }^{34}$ These changes may have altered the acceptability and cost of accessing tobacco, leading adolescents to evolve access strategies that could counter efforts to reduce youth initiation. To assess this question, we examined how trends in adolescents' tobacco supply sources varied over the period 2006-2012.

\section{METHODS \\ Sample}

The data came from an annual survey of Year 10 students (14 and15-year-olds) undertaken by Action on Smoking and Health (ASH) New Zealand and funded by the New Zealand Ministry of Health. All New Zealand schools teaching Year 10 students are invited to participate in the survey; those consenting provide the survey to all their Year 10 students and those who agree to participate complete a two-page questionnaire during class time under the supervision of teaching staff. Since 2006 (the first year of our analysis), school-level participation rates have ranged between $44 \%$ and $58 \%$ and more than 25000 students have responded to the survey in each year. The results presented draw on the subsample who reported smoking when surveyed.

The demographic characteristics of the returned sample remained fairly stable between 2006 and 2010, when the survey was fielded in the second half of the year. However, in 2011 and 2012 the survey was fielded earlier in the school year, thus a lower proportion of students had turned 15 prior to completing the questionnaire. Comparison of sample characteristics with those of the Year 10 population available from the New Zealand Ministry of Education also shows some systematic over-response by New Zealand Europeans and under-response by those in lower socioeconomic status (SES) groups. Consequently, the data were weighted by age, ethnicity and school SES to remove these influences 
from trend analyses (see Healey $e$ t $a i^{5}$ for a full account of survey response rates and sample demographic characteristics). In 2012, the data collection occurred while legislation banning display of tobacco products in retail stores was taking effect (July 2012).

\section{Measures}

The ASH questionnaire incorporates and extends some key measures from the international Global Youth Tobacco Survey relating to smoking and cessation behaviour, susceptibility and exposure to second-hand smoke. It collects standard demographic data (age, gender and ethnicity), the smoking status of family and friends and attitudes towards specific tobacco control issues. Although a portion of questions change from year to year, a core set of questions about smoking behaviour have remained consistent to enable monitoring of trends over time.

The core variable examined here-supply of cigarettes -was collected using the following question: During the past 30 days (1 month) how did you usually get your own cigarettes? From 2006 to 2010 four response options were provided:

1. I bought them from a shop;

2. I got them from friends;

3. I got them from my parents or caregivers;

4. I got them some other way.

In 2011 and 2012, the question remained unchanged but the response categories were expanded to the following:

1. I bought them from a shop;

2. I bought them from a vending machine;

3. I bought them from a friend/friends or person my age;

4. A friend/friends or person my age gave them to me;

5. A parent or caregiver gave them to me;
6. I took them from a parent or caregiver without asking;

7. I got them from an older brother or sister;

8. I got them some other way.

For the purposes of trend analyses, we combined purchases from a shop and vending machine, purchases and gifts from friends, and receiving or taking cigarettes from parents or caregivers, and included cigarettes received from an older sibling with obtaining tobacco some other way. This process created approximately comparable categories for 2011 and 2012 to those used from 2006 to 2010. We note also that the options involving friends were modified to friends or person my age (rather than just friends) in 2011-2012, and discuss the implications of this and other question wording changes later.

\section{Analyses}

All analyses were performed using SAS V.9.3 or SPSS V.21 software. Significance tests were two-sided, with $\mathrm{p}<0.05$ considered statistically significant unless otherwise stated. In addition to weighting estimates by ethnicity and school SES indicator, confidence limits and significance levels were adjusted for clustering at the school level. The data were as outlined above.

\section{RESULTS}

\section{Sample characteristics}

We categorised smokers (defined as smoking at least monthly) as either 'regular'-those who reported smoking daily or weekly—or 'intermittent'-those who reported smoking less than weekly - to create a dichotomous 'smoker status' variable. Table 1 contains details of smokers' characteristics across all survey years.

\begin{tabular}{|c|c|c|c|}
\hline \multirow{2}{*}{ Characteristics } & \multicolumn{2}{|l|}{ Smoker status* } & \multirow{2}{*}{$\begin{array}{l}\chi^{2} \\
\text { Significant at } p\end{array}$} \\
\hline & Regular smoker (\%) & Intermittent smoker (\%) & \\
\hline \multicolumn{4}{|l|}{ Age } \\
\hline $15(n=3553)$ & 21.8 & 78.2 & \multirow[t]{2}{*}{$<0.05$} \\
\hline $14(n=5680)$ & 19.8 & 80.2 & \\
\hline \multicolumn{4}{|l|}{ Gender } \\
\hline Female $(n=4596)$ & 22.8 & 77.2 & \multirow[t]{2}{*}{$<0.01$} \\
\hline Male $(n=4636)$ & 18.3 & 81.7 & \\
\hline \multicolumn{4}{|l|}{ Ethnicity } \\
\hline Māori $(\mathrm{n}=3774)$ & 27.5 & 72.5 & \multirow[t]{5}{*}{$<0.01$} \\
\hline Pacific $(n=1224)$ & 18.7 & 81.3 & \\
\hline European ( $n=3629)$ & 15.4 & 84.6 & \\
\hline Other $(n=231)$ & 12.1 & 87.9 & \\
\hline Asian $(n=374)$ & 11.8 & 88.2 & \\
\hline \multicolumn{4}{|l|}{ School-based SES } \\
\hline Low: decile 1-3 $(n=2646)$ & 26.8 & 73.2 & \multirow[t]{3}{*}{$<0.01$} \\
\hline Medium: decile 4-7 $(n=4157)$ & 19.7 & 80.3 & \\
\hline High: decile $8-10(n=2428)$ & 15.2 & 84.8 & \\
\hline
\end{tabular}


Regular smokers were more likely to be older and woman; however, the largest differences are between ethnicities and SES. The proportion of Māori (the indigenous people of New Zealand) who were regular smokers was 12 percentage points higher than for Europeans (and 15 percentage points higher than for Asians), a higher proportion of Pacific respondents were also regular smokers. These patterns are reflected in the SES findings; predictably, respondents with medium SES or low SES were more likely to be regular smokers than those with high SES; this difference is particularly marked for those with low SES.

\section{Trends in source of supply}

Between 2006 and 2012 smoking prevalence among young people declined by $8.1 \%$ (the linear trend coefficient was $-0.74 ; 95 \%$ CI -1.03 to -0.45 , significant $\mathrm{p}<0.01$ ), consequently 14-15-year-olds sourced less tobacco from all sources over this period. Our analyses examine whether and how the importance of different sources changed among smokers as prevalence declined. Figure 1 shows the trends in sources of supply from 2006 to 2012. The trend line dummy variables representing 2011-2012 compared to 2006-2010 are significant at $\mathrm{p}<0.01$ for 'friends' and 'caregivers', and at $\mathrm{p}<0.05$ for 'others', but non-significant for 'shop'.

Between 2006 and 2010, the supply source pattern did not change greatly. However, in 2011 the importance of friends as a source of supply decreased significantly (friends still accounted for nearly half of the reported supply), while the proportion of young people reporting they obtained tobacco from caregivers and other sources increased significantly. This pattern continued in 2012, though more data points are required to assess whether this is the start of a long-term downward trend or whether the supply sources have settled at new levels.

\section{Determinants of supply source}

To examine the determinants of social supply further, we developed binary logistic regression models using

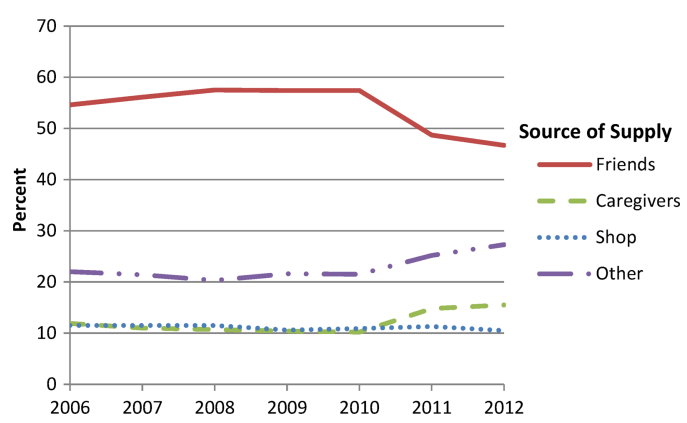

Figure 1 Trends in source of supply: 2006-2012. Note: friends: bought from or given to by friends/peers; from 2011 friends/peers my age. Caregivers: given to by parents/ caregivers, took from parents/caregivers without asking. Shop: bought from shop or vending machine. Other: other source or got from older siblings. data from the 2012 survey (the latest available year with all response options) to examine whether sources varied by respondents' demographic attributes and smoking behaviour.

The dependent variables were dichotomous $(0,1)$ variables representing the particular source of supply. The independent variables included current smoking status (ie, intermittent or regular smoker) and demographic characteristics that are associated with smoking prevalence: age, gender, SES (of the school the student attended, determined by its decile rating) and ethnicity. In addition, because we suspected an interaction between ethnicity and gender and source of supply, an ethnicity $\times$ gender interaction term was also included as an independent variable.

The logistic regression models were developed by systematically excluding non-significant variables until only significant variables remained. The ORs from these regression models are reported in table 2.

Regular smokers were significantly more likely than intermittent smokers to report having either purchased tobacco or received it from their parents, but less likely to have been given it by friends or taken it from their parents (in 2012, 20.5\% of regular smokers got their cigarettes from a shop or vending machine, $12.5 \%$ were given them by their parents or caregivers, $18.1 \%$ were given them by their friends and $6.2 \%$ took them from their parents; compared with $5.2 \%, 3.7 \%, 44.8 \%$ and $10 \%$, respectively, for intermittent smokers). The analyses by age mirror these results and show that 15-year-old smokers were more likely than 14-year-olds to have bought tobacco from a store or been given it by their parents, and less likely to have been given it by friends.

Men and women differed in their supply sources; men were more likely to have purchased tobacco, either from friends or commercial sources, while women were more likely to have been given tobacco by friends, but less likely to obtain it from other sources. Mid-SES respondents were significantly less likely to have purchased tobacco from a store and low-SES respondents were significantly less likely to have been given tobacco by friends.

Māori students were less likely than other students to report being given tobacco by friends, but there were several significant interactions between ethnicity and main tobacco supply sources. These interactions are more easily seen and understood in the cross-tabulations reported in table 3. Pacific females were between $50 \%$ and $100 \%$ more likely than any other gender-ethnicity group to report purchasing tobacco from friends or peers. Māori female respondents were more than twice as likely as other female respondents to have been given cigarettes by their parents or caregiver, while Pacific females were about $50 \%$ more likely to have been given cigarettes by an older sibling. Overall, 'trading' (buying cigarettes from friends) and older siblings are key supply 
Table 2 Significant ORs for logistic regression analyses of main tobacco supply sources

\begin{tabular}{|c|c|c|c|c|c|c|c|}
\hline \multirow[b]{2}{*}{ Attributes } & \multicolumn{7}{|c|}{ OR (95\% Cl) for each main tobacco supply source } \\
\hline & $\begin{array}{l}\text { Bought from } \\
\text { shop }(n=447)\end{array}$ & $\begin{array}{l}\text { Bought from } \\
\text { friends }(n=474)\end{array}$ & $\begin{array}{l}\text { Given to by } \\
\text { friends }(n=1506)\end{array}$ & $\begin{array}{l}\text { Given to by } \\
\text { parents }(n=289)\end{array}$ & $\begin{array}{l}\text { Took from } \\
\text { parents }(n=369)\end{array}$ & $\begin{array}{l}\text { Got from older } \\
\text { siblings }(n=275)\end{array}$ & $\begin{array}{l}\text { Other supply } \\
\text { source }(n=885)\end{array}$ \\
\hline \multicolumn{8}{|l|}{ Smoker status } \\
\hline $\begin{array}{l}\text { Intermittent } \\
\text { smoker }\end{array}$ & 1.00 & & 1.00 & 1.00 & 1.00 & & \\
\hline Regular smoker & $4.62^{\star *}(3.48$ to 6.14$)$ & & $0.29^{\star *}(0.24$ to 0.34$)$ & $3.03^{\star \star}(2.12$ to 4.32$)$ & $0.55^{\star \star}(0.42$ to 0.72$)$ & & \\
\hline \multicolumn{8}{|c|}{ (1, } \\
\hline 14 & 1.00 & & 1.00 & 1.00 & & & \\
\hline 15 & $1.42^{\star \star}(1.12$ to 1.81$)$ & & $0.74^{\star \star}(0.63$ to 0.87$)$ & $1.54^{\star *}(1.14$ to 2.07$)$ & & & \\
\hline \multicolumn{8}{|c|}{ 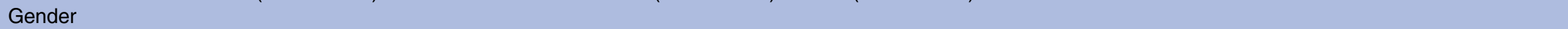 } \\
\hline Male & 1.00 & 1.00 & 1.00 & & & & 1.00 \\
\hline Female & $0.62^{*}(0.40$ to 0.94$)$ & $0.58^{* *}(0.43$ to 0.78$)$ & $1.48^{\star *}(1.25$ to 1.74$)$ & & & & $0.75^{\star \star}(0.32$ to 0.90$)$ \\
\hline \multicolumn{8}{|c|}{ Socioeconomic status $\dagger$} \\
\hline Medium & $0.57^{\star *}(0.39$ to 0.83$)$ & & & & & & \\
\hline Low & & & $0.69^{\star \star}(0.57$ to 0.83$)$ & & & & \\
\hline \multicolumn{8}{|l|}{ Ethnicity } \\
\hline Māori & & & $0.69^{\star \star}(0.57$ to 0.82$)$ & & & & \\
\hline \multicolumn{8}{|l|}{ Genderxethnicity $\dagger$} \\
\hline Female Māori & & $1.44^{\star}(1.01$ to 2.06$)$ & & $1.99^{\star *}(1.45$ to 2.73$)$ & & & \\
\hline Female Pacific & $0.50^{*}(0.27$ to 0.91$)$ & $2.97^{\star \star}(1.90$ to 4.64$)$ & & & & $1.77^{\star \star}(1.20$ to 2.64$)$ & \\
\hline
\end{tabular}

${ }^{*}$ Coefficient significant at $\mathrm{p}<0.05 ;{ }^{* *}$ coefficient significant at $\mathrm{p}<0.01$.

tReference category is the omitted categories in each case. 
Table 3 Source of supply in 2012 by gender and ethnicity

\begin{tabular}{|c|c|c|c|c|c|c|c|}
\hline \multirow[b]{3}{*}{$\begin{array}{l}\text { Source of } \\
\text { supply }\end{array}$} & \multicolumn{6}{|c|}{ Percentage of identifying source as most frequently used } & \multirow[b]{3}{*}{$\begin{array}{l}\chi^{2} \text { Significan } \\
\text { at } p\end{array}$} \\
\hline & \multicolumn{3}{|l|}{ Male } & \multicolumn{3}{|l|}{ Female } & \\
\hline & $\begin{array}{l}\text { European/other } \\
(n=1004)\end{array}$ & $\begin{array}{l}\text { Māori } \\
(n=769)\end{array}$ & $\begin{array}{l}\text { Pacific } \\
(n=263)\end{array}$ & $\begin{array}{l}\text { European/other } \\
(\mathrm{n}=935)\end{array}$ & $\begin{array}{l}\text { Māori } \\
(n=985)\end{array}$ & $\begin{array}{l}\text { Pacific } \\
(n=291)\end{array}$ & \\
\hline $\begin{array}{l}\text { Given to by } \\
\text { peers/friends }\end{array}$ & 36.1 & 24.2 & 30.2 & 47.6 & 33.1 & 36.8 & $<0.05$ \\
\hline $\begin{array}{l}\text { Bought from } \\
\text { peers/friends }\end{array}$ & 10.8 & 12.9 & 13.7 & 7.1 & 11.1 & 19.6 & $<0.01$ \\
\hline $\begin{array}{l}\text { Bought from } \\
\text { shop/machine* }\end{array}$ & 11.8 & 15.7 & 15.6 & 7.9 & 8.0 & 4.5 & NS \\
\hline $\begin{array}{l}\text { Given to by } \\
\text { parents }\end{array}$ & 5.9 & 5.9 & 5.3 & 4.3 & 12.3 & 3.8 & $<0.01$ \\
\hline $\begin{array}{l}\text { Took from } \\
\text { parents }\end{array}$ & 8.4 & 10.4 & 6.5 & 9.8 & 7.7 & 6.9 & NS \\
\hline $\begin{array}{l}\text { Given to by } \\
\text { older siblings }\end{array}$ & 6.4 & 4.7 & 6.9 & 5.7 & 7.5 & 10.7 & $<0.01$ \\
\hline Other & 20.6 & 26.2 & 21.8 & 17.6 & 20.3 & 17.7 & NS \\
\hline Total & 100.0 & 100.0 & 100.0 & 100.0 & 100.0 & 100.0 & \\
\hline
\end{tabular}

routes for Pacific females while parents and caregivers are an important source for Māori females.

\section{DISCUSSION}

We explored whether adolescent smokers' tobacco sources changed over a 7-year period that encompassed several policy changes, particularly between 2010 and 2012. During this period, smoking prevalence declined significantly, meaning fewer adolescents sourced cigarettes via either commercial or social routes. Examining whether and how patterns in supply varied as the policy environment changed provides insights into the measures required to reduce further youth smoking prevalence.

Irrespective of whether they were regular or intermittent smokers, and regardless of their demographic attributes, New Zealand adolescents who smoke obtain tobacco from friends more than any other source. This finding is consistent with international literature and earlier New Zealand-based research, highlighting the role of peers in supplying tobacco to experimental smokers. ${ }^{8} 17 \quad 30$ While friends remained the primary source of tobacco, they declined in relative importance following excise tax increases in New Zealand from 2010 onwards, while parents and caregivers became relatively more important. We cannot establish causality from these cross-sectional data; however, the more rapid declines in reported smoking from 2010 onwards have two implications. First, reducing social supply from friends may have contributed to the declines observed in smoking prevalence; second, as smoking prevalence decreases in response to other policy measures, fewer adolescents smoke and can act as supply sources for others.
As experimental smokers evolve into more regular smokers and age just 1 year (from 14 to 15), they become significantly more likely to report purchasing tobacco from stores. Future work could explore whether, as international studies suggest, New Zealand adolescents meet their growing need for nicotine by cultivating willing retailers who are less likely to require them to provide ID before making tobacco sales. ${ }^{28}$

Evidence of complicit retailers could have two potential policy implications that merit further analysis. First, it may imply a need for stricter enforcement of youth access restrictions. ${ }^{14}$ However, we suggest benefits of more intensive monitoring are likely to be less than those gained from comprehensive endgame restrictions on tobacco availability. Discussion of tobacco endgames has increased rapidly over the past 5 years ${ }^{36}$; several countries, including New Zealand, have established dates by which governments aim to have created essentially smoke-free nations (ie, where smoking prevalence is negligible)..$^{37}$ Endgame strategies vary and range from excise tax increases ${ }^{39}$ through to more stringent supply regulations. ${ }^{40}$ The latter option may have a greater impact on social supply to youth, ${ }^{27} 40$ and would increase smoking denormalisation. ${ }^{40}$ For example, having fewer tobacco retailers, restricting youth access to these outlets and not allowing stores located near schools to sell tobacco, would reinforce perceptions of tobacco as an abnormal product and make it more difficult for adolescents or their proxies to obtain. ${ }^{40}$ These measures could also impede development of 'black markets' where adolescents on-sell tobacco to others. ${ }^{25}$ Given that trading in cigarettes is particularly important for Pacific females, reductions in this source could also help ameliorate wider health inequalities, at least in New Zealand. 
A retail denormalisation strategy also appears more likely than increased monitoring to prompt cessation among adolescents' families, thus diminishing their potential to supply tobacco to older adolescents and those smoking regularly. More generally, denormalisation could contribute to other environmental changes likely to reduce adolescents' exposure to smoking and their risk of smoking initiation. For example, a denormalisation strategy could reinforce existing messages about the undesirability of smoking around children and exposing them to tobacco products, and by increasing public awareness of and support for New Zealand's smoke-free 2025 goal, make supplying children with tobacco increasingly unacceptable. This approach could be particularly beneficial to female Māori and Pacific adolescents, who are more likely to receive tobacco from caregivers or older siblings. In addition, regular and larger excise tax increases would heighten the economic burden of supplying tobacco to others and make it a less easily gifted product. ${ }^{22}$

More generally, denormalisation strategies that reduce the appeal, availability and accessibility of tobacco have had population-wide effects that influence adolescents. ${ }^{22}$

Perceptions that tobacco is difficult to access and consume are associated with reduced smoking experimentation ${ }^{16}$ and decreased opportunities for social exchange. ${ }^{17}$ These findings suggest comprehensive measures that decreased social acceptability of smoking and reduced adult smoking prevalence could foster reductions in adolescent smoking, and merit further investigation. ${ }^{12} 1729$

Our study has some limitations, particularly the changes in question response categories noted, which mean it is possible the observed changes in sources of supply reflect differences in the survey question rather than changes in respondents' behaviour. However, we note that the question wording changes were relatively minor and that an unchanged survey question suggests respondents' smoking behaviour did change in 2011. Between 1999 and 2010 the prevalence of current smoking among 14-15 year-olds declined steadily by $0.8 \%$ a year; however, in 2011 the rate of decline increased to $3.4 \%$, four times the previous rate. ${ }^{33}$ This difference is significant at the $10 \%$ level (the coefficient for the trend-line dummy variable representing 20112012 compared with $1999-2010$ was -2.96 ; (5\% CI -6.31 to 0.39 , significant at $\mathrm{p}<0.10$ ). Thus it seems reasonable to assume that smoking prevalence and source of supply changed in 2011, and that these changes were related to other influences, such as price.

The questions used ask smokers about their usual source of tobacco, not all their supply sources. While the overall patterns observed are consistent with international findings, further data are required to estimate whether new trends are evolving in relation to friends, parents and caregivers. Furthermore, the ASH surveys did not explore 'other' sources, though the research literature identifies willing strangers (particularly those who were themselves adolescent smokers) as important supply sources. ${ }^{28} 29$ Future research could examine sources beyond peers, parents and immediate siblings in greater detail, since this ambiguous route is second in importance only to friends. Further studies could also explore population density effects, although the consistently low proportions reporting purchase from retail outlets suggests this variable has declined in importance.

Our results raise the opportunity to examine how endgame measures that promote reductions in adult and peer smoking could affect overall youth smoking prevalence. More specifically, we suggest future research could estimate the likely effects of additional supply-side restrictions that make tobacco more difficult to obtain commercially and more burdensome to supply socially. Although we did not directly examine the effectiveness of youth access restrictions, evidence that around 10\% of respondents consistently reported making tobacco purchases from stores suggests implementation remains imperfect. The limited opportunities for further benefit to come from additional monitoring raises the question of whether reducing the number of outlets supplying tobacco could have more potential to decrease commercial supply. Retail endgame measures such as limiting tobacco retailer numbers would also refocus attention back onto the tobacco industry, which arguably benefits from current youth access policies. ${ }^{1} 131640$

\section{CONCLUSIONS}

Reducing smoking experimentation and subsequent uptake among adolescents is crucial to realisation of tobacco endgame strategies and requires reductions in tobacco supply. Since adolescents' friends and peers remain a consistently important source of tobacco, policymakers need to reduce the ease with which young people acquire and supply tobacco. Potential measures that merit more scrutiny include restricting the number of tobacco outlets and implementing regular and larger excise tax increases, both of which would make it more difficult for young people to afford, access and supply tobacco. Denormalisation campaigns that further reduce the social acceptability of smoking may also make young people less likely to consume tobacco. New Zealand's goal of being a smoke-free nation by 2025 offers a unique opportunity to introduce and evaluate progressive policies that comprehensively reduce the accessibility and increase the costs of buying tobacco.

Acknowledgements The authors would like to thank Action on Smoking and Health (ASH) New Zealand (NZ) for supplying the data; they especially acknowledge the Health Promotion Agency for producing the survey instruments, managing the data collection process and setting up and maintaining the datasets.

Contributors RE conceptualised the study. BH assisted with initial data formatting. PG undertook the data analysis and wrote a first draft of the results. JH developed the manuscript with PG, and they are joint lead authors. LM contributed to the literature review. LM, RE and BH reviewed manuscript iterations. All authors approved the final version of the manuscript. 
Funding This research received no specific grant from any funding agency in the public, commercial or not-for-profit sectors.

Competing interests While the authors do not consider it a conflict of interest, we note that all authors have received funding from health research agencies and several have given expert advice to tobacco control policymakers.

Ethics approval Ethical approval for the ASH surveys was granted by the Ministry of Health Multi-regional Ethics Committee.

Provenance and peer review Not commissioned; externally peer reviewed.

Data sharing statement ASH NZ make the Year 10 data available to bona fide researchers; all data requests should be made directly to ASH NZ.

Open Access This is an Open Access article distributed in accordance with the Creative Commons Attribution Non Commercial (CC BY-NC 4.0) license, which permits others to distribute, remix, adapt, build upon this work noncommercially, and license their derivative works on different terms, provided the original work is properly cited and the use is non-commercial. See: http:// creativecommons.org/licenses/by-nc/4.0/

\section{REFERENCES}

1. Etter JF. Laws prohibiting the sale of tobacco to minors. Impact and adverse consequences. Am J Prev Med 2006;31:47-51.

2. Coombs J, Bond L, Van V, et al. "Below the Line": the tobacco industry and youth smoking. Australas Med J 2011;4:655.

3. Pierce JP, Gilpin E. How long will today's new adolescent smoker be addicted to cigarettes? Am J Public Health 1996;86:253-6.

4. Taioli E, Wynder EL. Effect of the age at which smoking begins on frequency of smoking in adulthood. N Engl J Med 1991;325:968-9.

5. Breslau N, Peterson EL. Smoking cessation in young adults: age at initiation of cigarette smoking and other suspected influences. $A m \mathrm{~J}$ Public Health 1996;86:214-20.

6. Altman DG, Foster V, Rasenick-Douss L, et al. Reducing the illegal sale of cigarettes to minors. JAMA 1989;261:80-3.

7. Harrison PA, Fulkerson JA, Park E. The relative importance of socia versus commercial sources in youth access to tobacco, alcohol, and other drugs. Prev Med 2000;31:39-48.

8. Darling H, Reeder A, McGee R, et al. Access to tobacco products by New Zealand youth. N Z Med J 2005;118:U1408.

9. Laugesen M, Scragg R. Changes in cigarette purchasing by fourth form students in New Zealand 1992-1997. N Z Med J 1999;112:379-83.

10. Rimpelä A, Rainio S. The effectiveness of tobacco sales ban to minors: the case of Finland. Tob Control 2004;13:167-74.

11. Friend KB, Lipperman-Kreda S, Grube JW. The impact of local US tobacco policies on youth tobacco use: a critical review. Open J Prev Med 2011:1:34.

12. Glantz SA. Limiting youth access to tobacco: a failed intervention. $J$ Adolesc Health 2002;31:301-2.

13. Ling PM, Landman A, Glantz SA. It is time to abandon youth access tobacco programmes. Tob Control 2002;11:3-6.

14. DiFranza JR. Which interventions against the sale of tobacco to minors can be expected to reduce smoking? Tob Control 2012;21:436-42.

15. DiFranza JR, Savageau JA, Fletcher KE. Enforcement of underage sales laws as a predictor of daily smoking among adolescents-a national study. BMC Public Health 2009;9:107.

16. Gilpin EA, Lee L, Pierce JP. Does adolescent perception of difficulty in getting cigarettes deter experimentation? Prev Med 2004;38:485-91.

17. Forster J, Chen V, Blaine T, et al. Social exchange of cigarettes by youth. Tob Control 2003;12:148-54.
18. Wolfson M, Forster JL, Claxton AJ, et al. Adolescent smokers' provision of tobacco to other adolescents. Am J Public Health 1997;87:649-51.

19. Thomson CC, Hamilton WL, Siegel MB, et al. Effect of local youth-access regulations on progression to established smoking among youths in Massachusetts. Tob Control 2007;16:119-26.

20. Landman A, Ling PM, Glantz SA. Tobacco industry youth smoking prevention programs: protecting the industry and hurting tobacco control. Am J Public Health 2002;92:917-30.

21. Stead L, Lancaster T. Interventions for preventing tobacco sales to minors. Cochrane Database Syst Rev 2005;(1):CD001497.

22. Craig MJ, Boris NW. Youth tobacco access restrictions: time to shift resources to other interventions? Health Promot Pract 2007;8:22-7.

23. Robinson LA, Dalton WT III, Nicholson LM. Changes in adolescents sources of cigarettes. J Adolesc Health 2006;39:861-7.

24. Glantz SA. Preventing tobacco use-the youth access trap. Am J Public Health 1996;86:156-8.

25. Marsh L, Dawson A, McGee R. "When you're desperate you'll ask anybody": young people's social sources of tobacco. Aust N Z J Public Health 2013;37:155-61.

26. Ribisl KM. Social sources of cigarettes for youth: broadening the research base. Tob Control 2003;12:115-16.

27. DiFranza JR, Coleman M. Sources of tobacco for youths in communities with strong enforcement of youth access laws. Tob Control 2001;10:323-8.

28. Robinson J, Amos A. A qualitative study of young people's sources of cigarettes and attempts to circumvent underage sales laws. Addiction 2010;105:1835-43.

29. White MM, Gilpin EA, Emery SL, et al. Facilitating adolescent smoking: who provides the cigarettes? Am J Health Promot 2005;19:355-60.

30. Widome R, Forster JL, Hannan PJ, et al. Longitudinal patterns of youth access to cigarettes and smoking progression: Minnesota Adolescent Community Cohort (MACC) study (2000-2003). Prev Med 2007;45:442-6.

31. Johnston LD, O'Malley PM, Terry-McElrath YM. Methods, locations, and ease of cigarette access for American youth, 1997-2002. Am J Prev Med 2004;27:267-76.

32. Rainio SU, Rimpelä $A H$. Home-based sourcing of tobacco among adolescents. Prev Med 2009;48:378-82.

33. ASH New Zealand. Factsheet 1 youth smoking data 2012 Secondary Factsheet 1 youth_smoking data 2012 2013. http://www. ash.org.nz/research-and-information/ash-research/ latest-ash-year-10-survey/

34. New Zealand Government. Government final response to report of the Māori Affairs Committee on Inquiry into the tobacco industry in Aotearoa and the consequences of tobacco use for Māori, presented to the House of Representatives in accordance with Standing Order 248 (J.1). In: Government NZ, ed. Wellington, 2011

35. Healey B, Hoek J, Wilson N, et al. Youth exposure to in-vehicle second-hand smoke and their smoking behaviours: trends and associations in repeated national surveys (2006-12). Tob Control Published Online First: 17 Sep 2013. doi:10.1136/tobaccocontrol2013-051124.

36. Thomson $\mathrm{G}$, Edwards R, Wilson $\mathrm{N}$, et al. What are the elements of the tobacco endgame? Tob Control 2012;21:293-5.

37. Maubach N, Hoek JA, Edwards R, et al. 'The times are changing': New Zealand smokers' perceptions of the tobacco endgame. Tob Control 2013;22:395-400.

38. Edwards R, Wilson N, Peace J, et al. Support for a tobacco endgame and increased regulation of the tobacco industry among New Zealand smokers: results from a National Survey. Tob Control 2013;22:e86-93.

39. Thomson $\mathrm{G}$, Wilson $\mathrm{N}$, Blakely $\mathrm{T}$, et al. Ending appreciable tobacco use in a nation: using a sinking lid on supply. Tob Control 2010;19:431-5.

40. Whyte $G$, Gendall P, Hoek J. Advancing the retail endgame: public perceptions of retail policy interventions. Tob Control 2014;23:160-6. 